\title{
A New Vision for Design of Steel Transmission Line Structures by Reliability Method
}

\author{
${ }^{1}$ Khalied A. Wahab Abdalla A. Alsamad, ${ }^{2}$ Salih Elhadi Mohamed Ahmed \\ Senior Structural Engineer, Deputy Manger, Al-Dahna Construction Company-Sudan. \\ Professor of structural engineering -Sudan University of Sciences and Technology,Sudan,
}

\begin{abstract}
A reliability design method for statically determinate and indeterminate steel transmission lines towers and poles is presented. The method is in a Load and Resistance Factor Design (LRFD) format. The nominal load and resistance values for design are obtained from the mean values of probability distribution functions describing wind speed, radial ice thickness and yield stress. The load and resistance involving the coefficient of variation of the above variables and a target reliability index. Several cases demonstrate that use of the equations results in steel line having an actual reliability index nearly equal to the target reliability index.

Probability of failure calculations by the methods of numerical integration and the design point method are discussed. The mathematical relationship between probability of failure and the reliability index is explained.
\end{abstract}

The analysis and design by computer program, using reliability method gives more safety and economical results.

Keywords: Steel Transmission Structure, Reliability, Design.

\section{Introduction:}

One motive for examining the design of steel utility truss is to seed a balance between initial costs and failure costs. A simplified graphical representation of this concept is shown.[1]

The concept of structural design has been undergoing radical changes in philosophy in the last several years. A large amount of research and development in this area has been and is being concentrated on the application of concepts of reliability analysis to design. Major research efforts have been conducted for several construction materials $[1,2,3]$, and have resulted in proposals for alternate reliability-based (often called probability- based design methodology).

The development of new concepts for design, involving some form of reliability assessment has resulted largely because of the better control of safety and economy they promise to provide.

. The specific research objective was to develop an improved design method which would result in structures being consistently closer to the optimum reliability level than possible using current methods,, while retaining the simplicity and low expense of use necessary for a practical design method. adjust $\alpha$.

. Similarly in reliability design or the distributions of R and S may be driven forwards or backwards to

Conventional design can lead to under designed (failure prone) or over designed (expensive) structures.

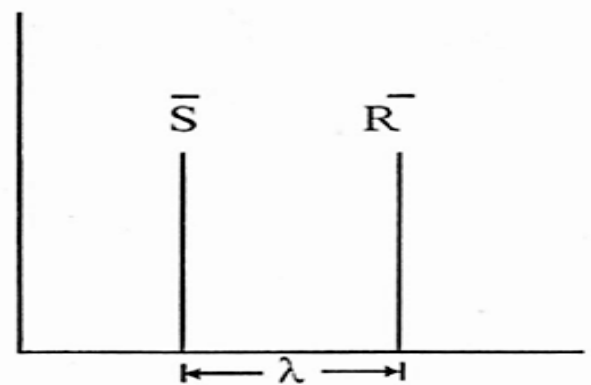

a. deterministic design

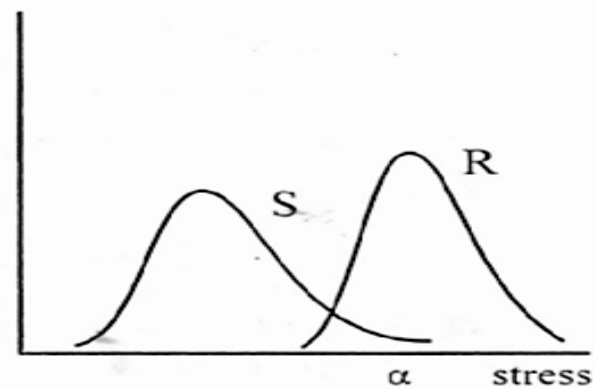

b. design including variance

Figure (1.1). Comparison of deterministic design and designIncluding variance.

1.1Steps of Solution:

* Study the design parameters covering the design(loads, resistance) to concepts of reliability.

* Study the mathematical of structural analysis of steeltransmission line towers.

- Study methods of calculation probability of failure including but-up of computer program.

* Determination the probability — based values for parameters covering the design (new proposed method). 


\subsection{Load and Resistance Factor Design:}

The uncertainty of structural performance due to variable loads and resistance can be compensated for designing with decreased values of resistance and increased loads. Loads or load effects can be increased, and resistance can be decreased, by applying load and resistance factors, respectively, to the nominal values of loads and resistance. A general design equation, with a summation for multiple loads, is written symbolically as:

$$
\phi \mathrm{R}>\mathrm{A}\left(\Sigma \gamma_{\mathrm{i}} \mathrm{P}_{\mathrm{i}}\right)
$$

Where $\gamma$ is a load factor usually greater than unity,

$\emptyset \quad$ is a resistance factor less than unity,

$\mathrm{R}$ is structural resistance however one chooses to quantify it,

$\mathrm{P}_{\mathrm{i}} \quad$ are generalized loads, and

A is the analysis that converts loads to load effects with dimensions comatible to those of $\mathrm{R}$.

\section{Problem Study}

Equation(1) is a design equation expressed in load and resistance factor design (LRFD) format see figure (1 and 2). The problem of assigning values to $\varnothing$ and $\gamma$ illustrates another major difference between conventional and reliability design. Load and resistance factors for conventional design have historically been ignored in favor of using factors of safety based on the judgment and past experience of members of professional engineering society committees. Reliability design on the other hand, uses the logical approach of basing the parameters of equation (1) $(\varnothing, \gamma, R, P)$ on the probability distributions of the load and resistance variables associated with the structure to be designed. figure (3)

Figure (1)

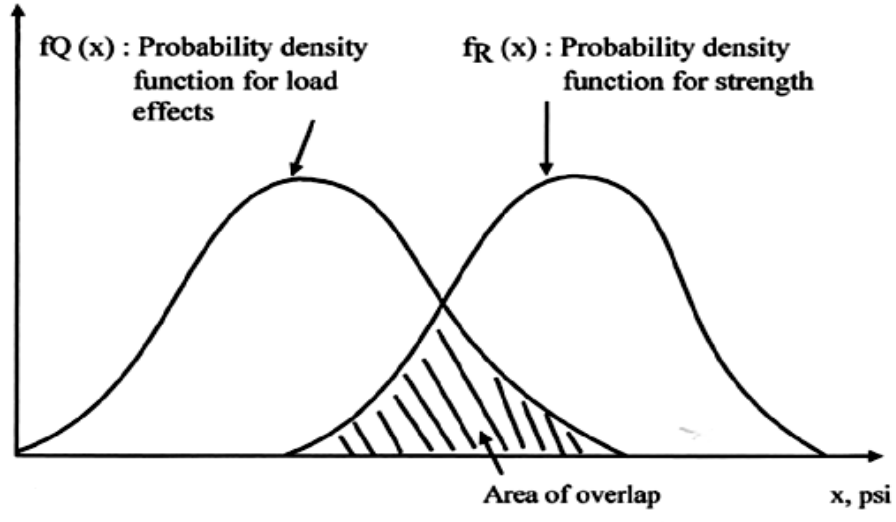

Figure 1.7a. Structural Reliabliity Diagram for Load Effects Q and Resistance R Model

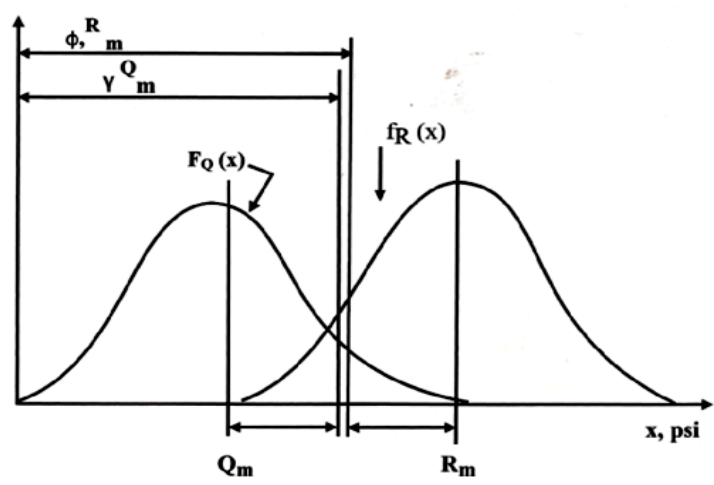

Figure (2) b Load and resistance factor design format 


$$
\begin{gathered}
\phi \mathrm{R}_{\mathrm{m}} \geq \gamma \mathrm{Q}_{\mathrm{m}} \\
\text { Where } \phi=\text { resistance factor, } \\
\mathrm{R}_{\mathrm{m}}=\text { mean resistance, } \\
\gamma \quad=\text { load factor }, \text { and } \\
\Phi_{\mathrm{m}}=\text { mean load effects }
\end{gathered}
$$

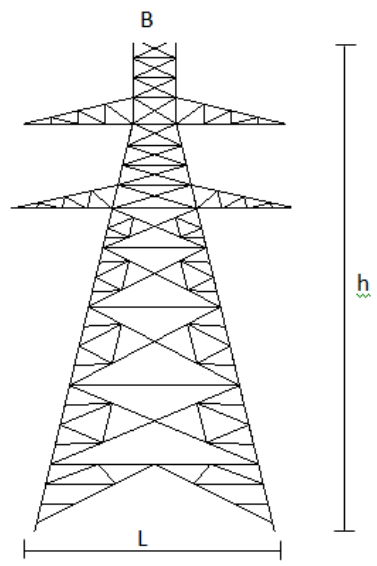

figure (3): The steel transmission tower

\subsection{Loading conditions}

To maximize stresses in tower members and loadings on foundations. The following loading combinations should be investigated.

\section{Intact loading case:}

1. Maximum transverse, maximum vertical.

2. Maximum transverse, minimum vertical.

3. Maximum transverse conductor, minimum transverse OHGA, minimum vertical.

4. Maximum transverse conductor, minimum transverse OGHA, minimum vertical.

5. Combination of vertical loads ( $\max$. and $\mathrm{min}$ ) to obtain vertical torsion (spans iced and bare).

6. Broken Wire (or other longitudinal) Loading. Taking maximum longitudinal and vertical and minimum for the point from (1 -5) above.

\subsection{Analysis of the Study Problem (deterministic design):}

Generally, the program assumes or the engineer inputs either assumed member sizes or areas of members into the three-dimensional elastic analysis program after the forces are distributed based on satisfying statics and the stiffness matrix, the members are sized. It the size of the members now selected vary considerably from the original assumed sizes, a reanalysis should be conducted to determine the extent to which the load distribution has changed, if at all, deterministic design for tower S60 is shown below:

It would appear that a "catch 22" can and does exist in some areas of the tower, for inatance, let us assume that we have a crossarm where the hanger and main corssarm members can take tension and compression. Let us also assume that only a longitudinal load is applied.

Thus, in this study failure is assumed to occur when either of the events below occur:

1. The maximum plastic bending stress along the tower or pole exceeds the modulus of plasticity (MOP) of the tower or pole.

2. The maximum bending deflection along the tower or pole an arbitrarily defined allowable limit.

3. The range of safety against overturning limit is less than the factor of safety by second moment method.

\section{Computer Program}

(Tower member Design, Analysis, and Reliability) is a FORTRAN language computer program written by Folse.developed and new built-up done by the authorsto solve the problem.

Program is additionally capable of performing reliability analyses by either numerical integration or the design point method. The input requirements for these computations include the summary statistic and distribution type for each random variable affecting the structure to be analyzed. For steel poles and tower member design by reliability the random variables which must be described are wind, ice, and yield stress. The program can additionally accept variable modulus of elasticity data which are necessary for the analysis of tower member design by reliability. 

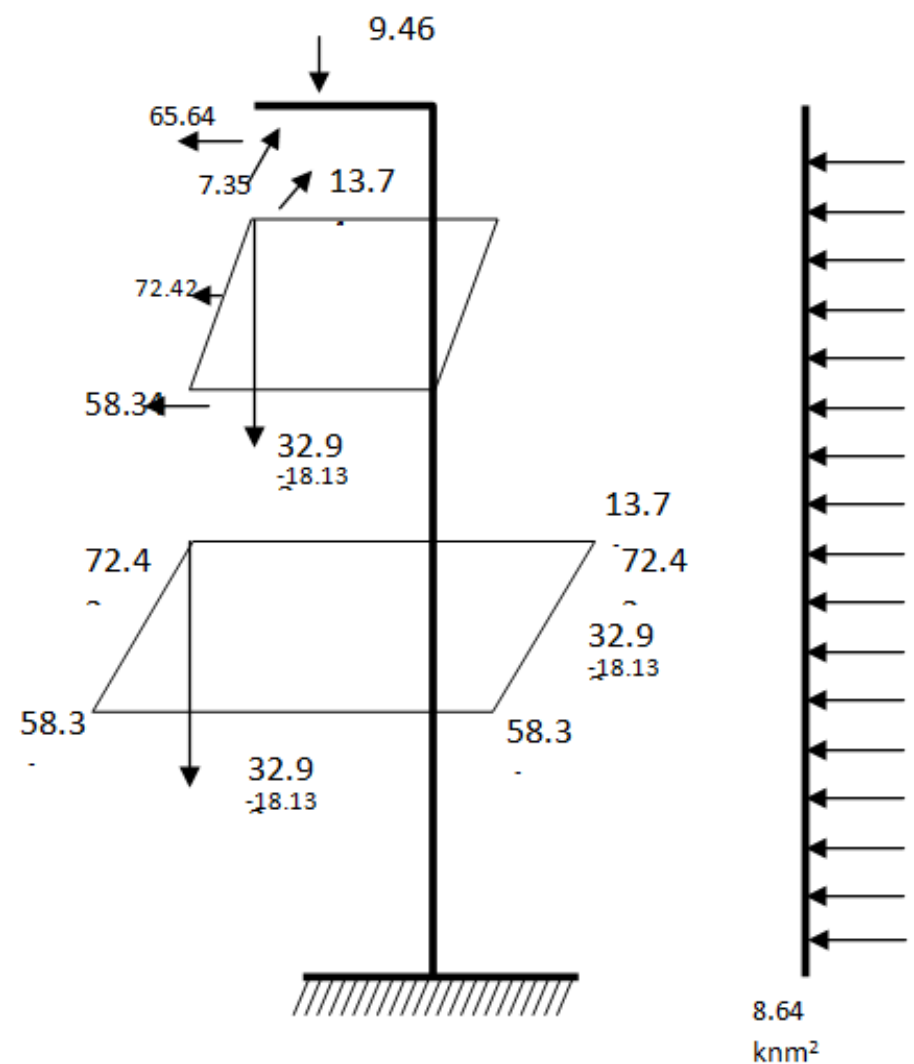

Loading cases for tower type one (S60) from experience of Sudanese work in the field of design of transmission line towers, table (1)

\begin{tabular}{|c|c|c|c|c|c|c|}
\hline No & Name & & $\begin{array}{l}\text { Line } \\
\text { angle }\end{array}$ & $\begin{array}{l}\text { vertical } \\
\text { loads }\end{array}$ & $\begin{array}{c}\text { Wind } \\
\text { direction }\end{array}$ & Unbalanced load \\
\hline 1. & Transverse Wind-max V & 'S60_90max' & 60 & Max & 90 & \\
\hline 2. & Transverse Wind-uplift & 'S60_90min' & 60 & Min & 90 & \\
\hline 3. & Wind at $45^{\circ} \cdot \max V$ & 'S60_45max' & 60 & $\operatorname{Max}$ & 45 & \\
\hline 4. & Wind at $45^{\circ}$.upliftV & 'S60_45min' & 60 & Min & 45 & \\
\hline 5. & Reverse Wind-max V & 'S60_270max' & 30 & Max & 270 & \\
\hline 6. & Reverse Wind-uplift V & 'S60_270min' & 30 & Min & 270 & \\
\hline 7. & $\begin{array}{l}\text { Earthwire+ Top conductor broken } \\
-\max \mathrm{V}\end{array}$ & 'S60_EWTC90max' & 60 & Max & 90 & $\begin{array}{l}\text { Earthwire+top conductor } \\
\text { (left side) }\end{array}$ \\
\hline 8. & $\begin{array}{lrrr}\begin{array}{l}\text { Earthwire }+ \\
\text { broken - Toplift }\end{array} & \text { Top conductor } \\
\end{array}$ & 'S60_EWTC90min' & 60 & Min & 90 & $\begin{array}{l}\text { Earthwire+top conductor } \\
\text { (left side) }\end{array}$ \\
\hline 9. & $\begin{array}{l}\text { Earthwire }+ \text { Middle conductor } \\
\text { broken }-\max V\end{array}$ & 'S60_EWMC90max' & 60 & Max & 90 & $\begin{array}{l}\text { Earthwire+middle } \\
\text { conductor (right side) }\end{array}$ \\
\hline 10. & $\begin{array}{l}\text { Earthwire }+ \text { Middle conductor } \\
\text { broken - uplift }\end{array}$ & 'S60_EWMC90min' & 60 & Min & 90 & $\begin{array}{l}\text { Earthwire+middle } \\
\text { conductor (right side) }\end{array}$ \\
\hline 11. & $\begin{array}{l}\text { Earthwire }+ \text { Bottom conductor } \\
\text { broken }-\max \mathrm{V}\end{array}$ & 'S60_EWBC90max' & 60 & $\operatorname{Max}$ & 90 & $\begin{array}{l}\text { Earthwire+bottom } \\
\text { conductor (lift side) }\end{array}$ \\
\hline 12. & $\begin{array}{l}\text { Earthwire }+ \text { Bottom conductor } \\
\text { broken -uplift }\end{array}$ & 'S60_EWBC90min' & 60 & Min & 90 & $\begin{array}{l}\text { Earthwire+bottom } \\
\text { conductor (lift side) }\end{array}$ \\
\hline 13. & $\begin{array}{l}\text { Top conductor+ } \text { Bottom } \\
\text { Conductor broken }-\max \mathrm{V}\end{array}$ & 'S60_TCBC90max' & 60 & $\operatorname{Max}$ & 90 & $\begin{array}{l}\text { Top }+ \text { bottom conductor } \\
\text { (left side) }\end{array}$ \\
\hline 14. & $\begin{array}{l}\text { Top conductor+ } \quad \text { Bottom } \\
\text { Conductor broken - uplift }\end{array}$ & 'S60_TCBC90min' & 60 & Min & 90 & $\begin{array}{l}\text { Top }+ \text { bottom conductor } \\
\text { (left side) }\end{array}$ \\
\hline 15. & $\begin{array}{l}\text { Earthwire+ } \quad \text { Top Conductor } \\
\text { broken }- \text { max }\end{array}$ & 'S60_EWTC270max' & 30 & Max & 270 & $\begin{array}{l}\text { Earthwire+top conductor } \\
\text { (left side) }\end{array}$ \\
\hline 16. & $\begin{array}{l}\text { Earthwire }+ \text { Top Conductor } \\
\text { broken - uplift-rev.Wind }\end{array}$ & 'S60_EWTC270min' & 30 & Min & 270 & $\begin{array}{l}\text { Earthwire+top conductor } \\
\text { (left side) }\end{array}$ \\
\hline 17. & $\begin{array}{l}\text { Earthwire+ } \text { Middle Conductor } \\
\text { broken }- \text { max V-rev.Wind }\end{array}$ & 'S60_EWMC270max' & 30 & Max & 270 & $\begin{array}{l}\text { Earthwire+middle } \\
\text { conductor (right side) }\end{array}$ \\
\hline 18. & $\begin{array}{l}\text { Earthwire+ Middle Conductor } \\
\text { broken -uplift-rev.Wind }\end{array}$ & 'S60_EWMC270min' & 30 & Min & 270 & $\begin{array}{l}\text { Earthwire+ middle } \\
\text { conductor (right side) }\end{array}$ \\
\hline 19. & Earthwire + Bottom Conductor & 'S60_EWBC270max' & 30 & Max & 270 & Earthwire+bottom \\
\hline
\end{tabular}




\begin{tabular}{|c|c|c|c|c|c|c|}
\hline & broken-max V-rev.Wind & & & & & conductor (lift side) \\
\hline 20. & $\begin{array}{l}\text { Earthwire+ Bottom Conductor } \\
\text { broken -uplift-rev.Wind }\end{array}$ & 'S60_EWBC270min' & 30 & Min & 270 & $\begin{array}{l}\text { Earthwire+bottom } \\
\text { conductor (lift side) }\end{array}$ \\
\hline 21. & $\begin{array}{l}\text { Top Conductor }+ \\
\text { Conductor broken } \\
\text { rev.Wind }\end{array}$ & 'S60_TCBC270max' & 30 & Max & 270 & $\begin{array}{l}\text { Top }+ \text { bottom conductor } \\
\text { (left side) }\end{array}$ \\
\hline 22. & $\begin{array}{l}\text { Top Conductor }+ \text { Bottom } \\
\text { Conductor broken } \\
\text { rev.Wind }\end{array}$ & 'S60_TCBC270min' & 30 & Min & 270 & $\begin{array}{l}\text { Top }+ \text { bottom conductor } \\
\text { (left side) }\end{array}$ \\
\hline 23. & Cascade condition-max V & 'S60_casc_max' & 60 & Max & - & \\
\hline 24. & Cascade condition-uplift V & 'S60_casc_min' & 60 & Min & - & \\
\hline 25. & Temporary terminal condition & 'S60_temp' & 60 & Max & & \\
\hline 26. & Maintenance condition (left side) & 'S60_maint_left' & - & $\begin{array}{c}3 \\
\times \text { normal }\end{array}$ & & \\
\hline 27. & Maintenance condition & 'S60_maint' & - & $\begin{array}{c}3 \\
\times \text { normal } \\
\end{array}$ & & \\
\hline 28. & $\begin{array}{l}\text { Wind on tower (with ovedoad } \\
\text { factor for tower weight) }\end{array}$ & 'S60_wind_max' & - & - & 180 & \\
\hline 29. & $\begin{array}{l}\text { Wind on tower (without overload } \\
\text { factor for tower weight) }\end{array}$ & 'S60_wind_min' & - & - & 180 & \\
\hline
\end{tabular}

\section{Earth and wire}

Table (2): Most Critical loading cases number (1 and 2)

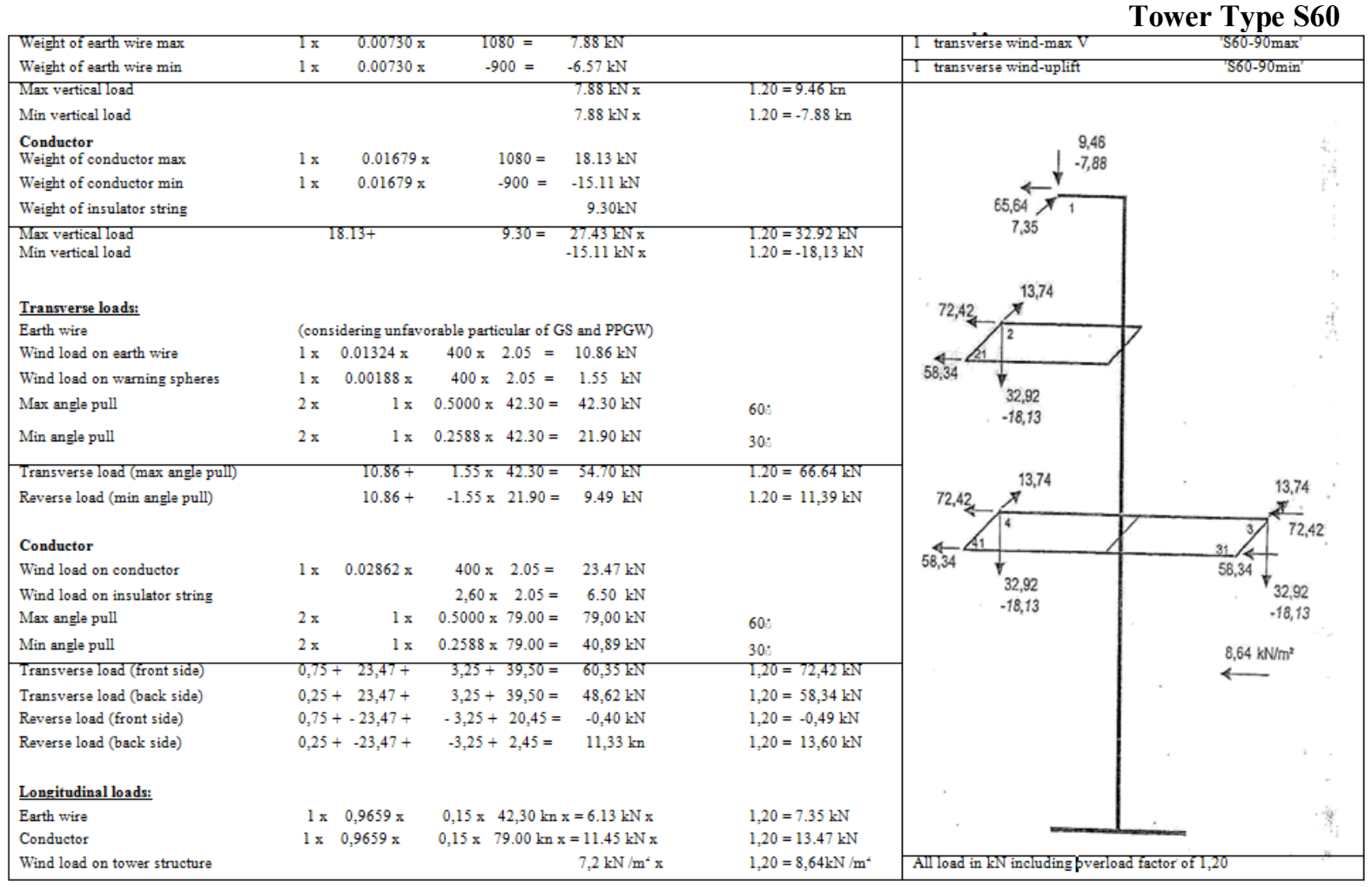

\section{Proposed analysis and design by reliability}

The design above show the determinist design of tower how can analyses by using many methods,

The proposed method proved a level of control over design of frame. the control of this design enables engineers to make the proper decisions when considered by the balance between structural survival and cost. The essential elements of this method include:

1) Use of LRFD equation.

2) Probability based design values of dead load, live load, and wind load.

Beam and column models of resistance (MOR) and models of elasticity (MOE).

3) The specification of target reliability index.

\subsection{Calculation of probability of failure:}

To calculate probability of failure one need to understand the meaning of failure

Failure will occur when the demand exceeds the capacity by referring to the performance function of mathematically as the event when $\mathrm{y}<0$ thus 
Since $y$ is a normal random variable we can calculate this

\subsection{Limit state Function:}

Table (3) Limit state function (data for load resistance factor design)

\begin{tabular}{|l|l|l|l|}
\hline \multicolumn{1}{|c|}{ Distribution } & \multicolumn{1}{c|}{ Coefficient } & $\lambda R=1.1$ & 1.11 \\
\hline R log normal & $\mathrm{VR}=13 \%$ & $\lambda_{D}=1.05$ & 1.25 \\
\hline D normal & $\mathrm{VD}=10 \%$ & $\lambda L=1.0$ & 1.02 \\
& & $\lambda W=2=1.01$ & 1.02 \\
\hline L Gmble I & $\mathrm{VL}=25 \%$ & $\lambda W=25 \%$ & $\mathbf{1 . 0}$ \\
\hline W I & $\mathrm{VW}=25 \%$ &
\end{tabular}

V. Reliability-Based Design of Transmission Towers Under Loads and Wind (proposed design)

Using equ. (3)

\section{Where:}

$$
\emptyset R n \geq \alpha_{\circ} D_{n}+\alpha L+\alpha_{W} w
$$

Rn resistance, D dead load, L live load, W wind load, $\Phi$ reduced factor Extrem type (Gbmle (1))

Then

$$
\begin{gathered}
\alpha=\sqrt{\frac{\pi 2}{b \sigma_{L}^{2}}}=\frac{\pi}{\sqrt{6}\left(v_{L} \mu_{L}\right)}=\frac{5.13}{\mu L}=\frac{1.710}{\mu_{D}} \\
U=\mu L \frac{0.577}{a}=3 \mu D-\frac{0.5772}{1.710 / \mu D}=2.66 \mu D
\end{gathered}
$$

$\mathrm{Fl}\left(1^{*}\right)=\exp (-\exp (-\alpha(1 *-\mathrm{U})))$

$\mathrm{fL}\left(1^{*}\right)=\alpha\left(\exp \left(-\mathrm{a}\left(1^{*}-\mathrm{u}\right)\right)\right) \exp (-\exp (-\mathrm{a}(1-\mathrm{u})))$

Substituting $\quad \mathrm{I}^{*}=3 \mu_{D}$ for the first iteration we get

$$
\mathrm{Fl}=\left(\mathrm{I}^{*}\right)=0.5706 \quad \mathrm{Fl}\left(\mathrm{I}^{*}\right)=\frac{0.5474}{\mu_{D}}
$$

Thus the equivalent parameter of $\mathrm{L}$, or $\sigma_{L}^{e}=0.5474, \mu_{L}^{e}=2.872 \mu_{D}$

Determine $(\mathrm{G})$ :

$$
\begin{aligned}
& G_{1}=-\frac{\partial g}{\partial_{R}} \sigma_{R}^{e} \quad=-\sigma_{R}^{e} \\
& G_{2}=-\frac{\partial g}{\partial_{R}} \sigma_{D} \text { Design point }=+\sigma_{R}^{2}=V_{o} \mu_{D} \\
& G_{3}=-\frac{\partial g}{\partial_{R}} \sigma_{D} \quad=+\sigma_{R}^{e} \\
& G_{3}=-\frac{\partial g}{\partial_{R}} \sigma_{L}^{E} \quad \text { Design point } \quad=+\sigma_{R}^{e}
\end{aligned}
$$




$$
\begin{aligned}
\sigma_{R}^{2} & =r^{*} V R=4 \mu(0.13)=0.52 \mu D \\
\mu_{R}^{e} & =r^{*}\left(1-\ln \left(r^{*}+\operatorname{Ln}(\mu R)\right)\right) \\
& \left.=r^{*}\left(1-\ln \left(\frac{r^{*}}{\mu R}\right)\right)=4 \mu .20\right) \\
\mu_{R}^{e} & =4 \mu D
\end{aligned}
$$

\section{Where}

$$
\begin{aligned}
& \sigma=\text { Standarddeviation } \\
& \mu_{R}=\text { Mean } \\
& \{\alpha\}=\frac{\rho(G)}{\sqrt{\left(G^{T}(\rho)(G)\right)}}
\end{aligned}
$$

Case (1):

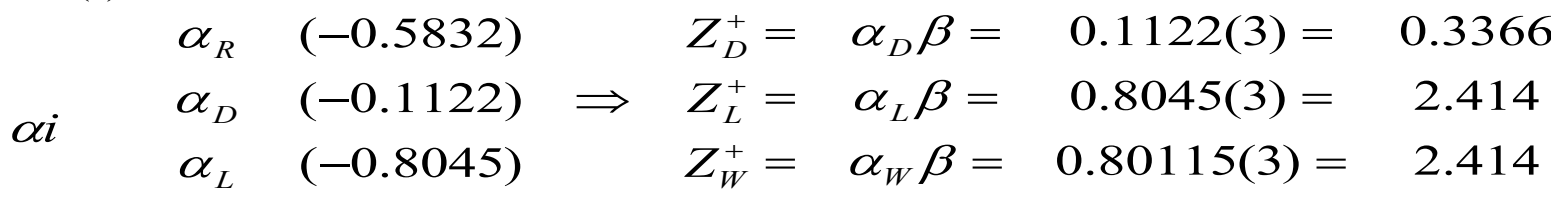

$$
\begin{aligned}
& \alpha_{W} \quad(-0.8045)
\end{aligned}
$$

Case (2):

$$
\begin{aligned}
& \alpha_{R}(-0.5832) \quad Z_{D}^{+}=\alpha_{D} \beta=0.1122(2.38)=0.267 \\
& \alpha i \quad \alpha_{D}(-0.1122) \Rightarrow Z_{L}^{+}=\alpha_{L} \beta=0.8045(2.38)=1.9147 \\
& \alpha_{L}(-0.8045) \quad Z_{W}^{+}=\alpha_{W} \beta=0.80115(2.38)=1.9147 \\
& \alpha_{W} \quad(-0.8045)
\end{aligned}
$$

5.1 Determine corresponding design point method:

$$
\begin{aligned}
& d^{*}=\mu D+Z_{D}^{*} \sigma_{D}^{*}=\mu_{D}\left(1+Z_{D}^{+} V_{D}\right)=\text { case } 1=1.034 \mu_{D} \quad \text { case } 2=1.0267 \\
& I^{*}=\mu_{l}^{e}+Z_{D}^{*} \sigma_{D}^{*}=2.872 \mu_{D}+2.414\left(0.717 \mu_{D}\right)=\text { case } 1=4.604 \mu_{D} \\
& \operatorname{case}(2)=\quad / / \quad 1.91471 / / \quad=\text { case } 2=4.243 \mu_{D} \\
& \mathrm{R}^{*}=\mathrm{d}^{*}+\mathrm{I}^{*} \\
& \mu R=\frac{r^{*}}{1+\alpha_{R} \beta V_{R}} \\
& \mu R=\frac{5.638 \mu_{D}}{1+(0.5832)(3)(9132.38)}=7.298 \mu_{D} \text { case } 1 \\
& \text { case } 2 \\
& \text { // } \\
& 2.38 \\
& =6.87932 \mu_{D}
\end{aligned}
$$




\subsection{Reduced factor:}

$$
\begin{aligned}
& \phi=\frac{r^{*}}{R_{n}}=\frac{r^{A}}{\mu_{R} / \lambda_{R}}=\lambda_{R} \frac{r^{A}}{\mu_{R}}=1.1 \frac{5.638 \mu D}{7.429 \mu D}=0.8498 \\
& \text { From table (3) } \quad \gamma_{D}=\lambda_{D} \frac{d^{*}}{\mu_{D}}=1.05 \frac{1.02 \mu_{D}}{\mu_{D}}=1.0710 \\
& \lambda=\quad \gamma_{L}=\lambda_{L} \frac{I^{*}}{\mu L}=(1.0) \frac{4.604 \mu D}{3 \mu D}=1.534667 \\
& \lambda=\quad \gamma_{w}=\lambda_{L} \frac{I^{*}}{\mu_{W}}=(1.01) \frac{4.6 .04 \mu_{D}}{3 \mu \mu_{D}}=1.5500 \\
& \phi R N \geq \gamma_{D} D_{n}+\alpha L_{L}+\alpha_{w} W_{n} \\
& \left((0.8498) R_{n} \geq(1.071) D_{n}+(1.53467) L_{n}+(1.55) w_{n}\right)
\end{aligned}
$$

Equation (7) is the result of work depend on critical loading condition and it give safety and economical design, the factor's is ruled to give ideal solution of the equation and all relations between loads are present in its critical

\begin{tabular}{|c|c|c|c|c|c|c|c|c|c|c|c|c|c|c|c|c|c|c|c|}
\hline \multirow{2}{*}{$\begin{array}{l}\frac{0}{2} \\
\frac{\pi}{20} \\
\left.\frac{\pi}{2}\right\}\end{array}$} & \multirow{2}{*}{$\begin{array}{c}\mathrm{X} \\
\text { dead } \\
\text { load } \\
(\text { cov) }\end{array}$} & \multirow{2}{*}{$\begin{array}{l}\alpha \text { live } \\
\text { load } \\
\text { (cov) }\end{array}$} & \multirow{2}{*}{$\begin{array}{l}\alpha \\
\text { wind } \\
\text { (cov) }\end{array}$} & \multirow{2}{*}{$\begin{array}{c}\alpha \\
\text { Resistance } \\
\text { (cov) }\end{array}$} & \multirow{2}{*}{$\begin{array}{c}\text { Target } \\
\beta\end{array}$} & \multirow{2}{*}{$\begin{array}{c}\beta \\
\text { index }\end{array}$} & \multicolumn{4}{|c|}{ Mean factory } & \multicolumn{2}{|c|}{$\begin{array}{c}\text { Resistant } \\
\text { Rn }\end{array}$} & \multicolumn{3}{|c|}{ Load } & \multirow{2}{*}{$\begin{array}{l}\text { Reduction } \\
\text { factor } \\
\text { (Ø) }\end{array}$} & \multirow{2}{*}{$\begin{array}{c}\begin{array}{c}\text { Dead } \\
\text { load } \\
\text { factor }\end{array} \\
\left(\gamma_{d)}\right.\end{array}$} & \multirow{2}{*}{$\begin{array}{c}\begin{array}{c}\text { Live } \\
\text { load } \\
\text { factor }\end{array} \\
\left(\gamma_{\mathrm{L})}\right.\end{array}$} & \multirow{2}{*}{ 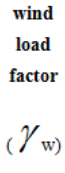 } \\
\hline & & & & & & & $\begin{array}{l}\lambda \\
R\end{array}$ & $\begin{array}{c}\lambda \\
\mathrm{w}\end{array}$ & $\begin{array}{l}\lambda \\
\mathrm{d}\end{array}$ & $\begin{array}{c}\lambda \\
1\end{array}$ & Steel & Conc & $\mathrm{Dn}$ & Ln & $\mathrm{Wn}$ & & & & \\
\hline 1. & $\begin{array}{l}0.112 \\
(0.1)\end{array}$ & $\begin{array}{c}0.55 \\
(0.0125)\end{array}$ & $\begin{array}{l}0.55 \\
(0.25)\end{array}$ & $-0.55(0.13)$ & 3 & $\begin{array}{c}1.726 \\
\text { not good }\end{array}$ & 1.1 & 1.01 & 1.05 & 1 & $\begin{array}{c}5.4 \\
\text { kip/m2 }\end{array}$ & 4.35 & $\begin{array}{c}0.6 \\
\mathrm{kip} / \mathrm{m}\end{array}$ & 0.5 & 0.45 & 0.86405 & 1.0853 & 1.4125 & 1.36578 \\
\hline 2. & $\begin{array}{l}09112 \\
(0.1)\end{array}$ & $\begin{array}{l}0.8 \\
(0.25)\end{array}$ & $\begin{array}{l}0.8 \\
(0.25)\end{array}$ & $-0.3832(0.13)$ & 3 & $\begin{array}{c}3.003 \\
\text { good }\end{array}$ & 1.1 & 1.01 & 1.05 & 1 & $\begin{array}{c}65.3 \\
\text { Kip/ft }\end{array}$ & 78.3 & 1.5 & 0.750 .55 & 0.55 & .0 .84981 & 1.08534 & 1.600 & 1.5475 \\
\hline 3. & $0.5(0.1)$ & $\begin{array}{l}0.75 \\
(0.25)\end{array}$ & $\begin{array}{l}0.75 \\
(0.25)\end{array}$ & $-0.583(0.13)$ & 3 & $\begin{array}{c}1.896 \\
\text { not good }\end{array}$ & 1.1 & 1.01 & 1.05 & 1 & 56 kip/t & 7414.3 & 0.61 & 0.22 & 0.67 & 0.84981 & 1.2075 & 1.56250 & 1.51079 \\
\hline 4. & $0.3(0.1)$ & $\begin{array}{l}0.65 \\
(0.25)\end{array}$ & $\begin{array}{l}0.65 \\
(0.25)\end{array}$ & $-0.65(0.13)$ & 3 & 1.785 & 1.1 & 1.01 & 1.05 & 1 & 56 kip/t & 7414.3 & 0.61 & 0.22 & 0.67 & 0.82115 & 1.1445 & 1.4875 & 1.43827 \\
\hline 5. & $\begin{array}{c}0.1122 \\
(0.1)\end{array}$ & $(0.25)$ & $\begin{array}{l}0.55 \\
(0.25)\end{array}$ & $-0.55(0.13)$ & 3 & 1.726 & 1.1 & 1.01 & 1.05 & 1 & $\begin{array}{l}51.4 \\
\text { kip/t }\end{array}$ & 4.33 & 0.68 & 0.67 & 0.53 & 0.86405 & 1.08528 & 1.4125 & 1.36576 \\
\hline
\end{tabular}
condition to be solved in load resistance format. Wright hand give loads combinations and left hand give the reduction factor and resistance while lead to final solution.

Result and comparisons using equation (7) are shown in table (4)

Table (4): Results and comparison between $\alpha$ i, $\beta$ target and $\beta$ index and reduction factor (Ø) and $\gamma_{\text {i factors }}$ for Equation (7)

\section{Discussions:}

The solution proposed by the authors has been compared with the ASCE-LRFD nd the korean-ASD and it was found that the solution was in godd agreement with these codes. Alengthy discussion regarding that has been given in reference (8).

VII. Conclusions:

1. This study consisted of the development of new vision for design of steel transmission line structures towrs and poles by reliability taking in consideriton many situation of loads effects and resistance by material of 
pole and towers and this development give the designer great control over probability of failure of structure used in transission line resolution of problems arising in the course of the development that a conversion by transmission line structure designers from current methods to a probability-based approach is both reasonable and beneficial.

2. The current method is characterised by over simplified load model and structural analysis and utilizes nominal loads and structural properties and safety factors which are difficult to relate to structural reliability. Therefore improved load models and structural analysis techniques were done for calculating the probability of failure of structure and factors were selected to complete the solution of design in good way.

3. The current methods of selecting factor design (LRFD) resulting structal relability to increase design control of reliability with good way to satisfy economy and safty.

\section{References}

[1] Aifredo H-s. Mg \& wilson H. Tang probability concepts in engineering planning and design volumel Basic principles. New york, London sydey, Toronto 1975 New print 2000.

[2] Andrzej S, Nowak and Kevin R. Collins, Reliability of Structures, University of Michigan, International Edition, 2000, by the Mc Graw-Hill companies, Library of Congress Cotaloging in publiscation.

[3] A-H-Sang and R-viliaverde. Structural engineering in natural hazards mitigation volume I held irvine caifornia, 2002.

[4] A-H-Sang and R-Vilaurede. Structural engineering in natural hazards mitigation. Volumell held Irvine california, 2002

[5] reliability designe steel transmission poles, structrual research repart.

[6] Egiptian Eng. For Technical constraction, Monopole Tower 30 m, January 2007.

[7] Studies of Merowe Dam Prject, Transmission Line Works, 2002-2007. Ministry of Electricity Sudan.।

[8] Abd-Alsamad, Khaid, A. Wahab, Design of transmission, M.Sc, thesis, Sudan University of science and technology, July 2011. 